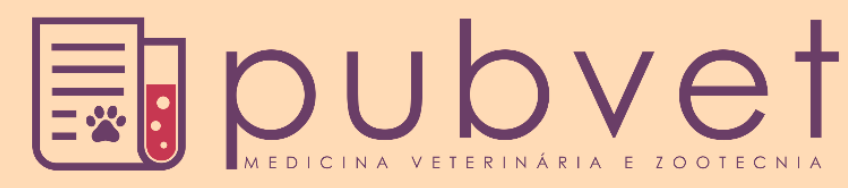

https://doi.org/10.31533/pubvet.v15n05a804.1-9

\title{
Timoma em cão: Relato de caso
}

\section{Taine Elia de Oliveira*1, Paula Papareli de Oliveira ${ }^{1}$, Elisangela Guedes Duarte ${ }^{1}$, Carolina Vianna Leite Otero', Verônica Garcez Araújo ${ }^{2}{ }^{\circ}$, Bruno De Tullio Augusto Roque Lima ${ }^{3} \bullet$}

'Discentes da Faculdade de Medicina Veterinária - Universidade São Judas Tadeu Campus Unimonte - Santos, SP. ${ }^{2}$ Professora da Faculdade de Medicina Veterinária - Universidade São Judas Tadeu Campus Unimonte - Santos, SP. ${ }^{3}$ Médico Veterinário, Mestre em Cirurgia, Doutor em Oncologia, Professor do Instituto Qualittas, Campinas, SP.

*Autores para correspondência, e-mail: taineeoliveira@gmail.com

Resumo. Timoma é um tumor que surge a partir de células do timo, um órgão presente em todos os mamíferos e responsável pela maturação de linfócitos $\mathrm{T}$, que regride de tamanho ao longo da vida, até que na idade adulta é gradualmente substituído por tecido adiposo. Tais tumores são mais comuns em animais idosos e os sinais clínicos associados a esse tipo de neoplasia são muitas vezes não específicos até que atinjam grandes proporções. Um diagnóstico preliminar de timoma é muitas vezes feito com base na localização do tumor e citologia aspirativa. Comparado a outros tipos de tumor que podem ocorrer nessa região, os timomas costumam ter bom prognóstico com o tratamento. $\mathrm{O}$ presente artigo relata $\mathrm{o}$ caso de uma cadela da raça Labrador Retriever de onze anos de idade, diagnosticada com timoma de origem epitelial, que como tratamento elegeu-se a timectomia através de toracotomia intercostal com ressecção de costela. O timoma foi identificado através de exames de imagem como radiografia torácica e tomografia computadorizada, pela citologia aspirativa e confirmado diagnóstico por meio de exame histopatológico. A paciente teve evolução favorável no pós-operatório e, até o momento, apresenta-se em ótimo estado geral.

Palavras-chave: Oncologia, timo, timectomia, toracotomia intercostal, toracotomia lateral

\section{Thymoma in dog: Case report}

Abstract. Thymoma is a tumor that arises from cells of the thymus, an organ present in all mammals, responsible for the maturation of $\mathrm{T}$ lymphocytes and that regresses in size throughout life, until in adulthood it is gradually replaced by adipose tissue. These tumors are more common in elderly animals and the clinical signs associated with this type of neoplasia are often non-specific until they reach large proportions. A preliminary diagnosis of thymoma is often made based on the location of the tumor and aspiration cytology. Compared to other types of tumor that can occur in this region, thymomas usually have a good prognosis with treatment. This article reports the case of a 10-year-old Labrador Retriever dog, diagnosed with thymoma of epithelial origin, who was treated as a thymectomy through intercostal thoracotomy with rib resection. Thymoma was identified through imaging exams such as chest radiography and computed tomography, by aspiration cytology and a diagnosis was confirmed through histopathological examination. The patient had a favorable evolution in the postoperative period and until now, she is in excellent general condition.

Keywords: Oncology, thymus, thymectomy, intercostal thoracotomy, lateral thoracotomy

\section{Introdução}

O timo é um órgão linfo epitelial localizado no mediastino de animais jovens. É essencial para o desenvolvimento e função do sistema imunológico, principalmente relacionada à maturação de linfócitos T, que constituem 70 a 80\% dos linfócitos no sangue periférico (Zachary et al., 2012). 
Em animais jovens, o timo se localiza entre os pulmões e ocupa um espaço bastante amplo do mediastino (Köning \& Liebich, 2011; Sisson et al., 1986). Já na puberdade, inicia-se uma involução progressiva do órgão até chegar à fase adulta do animal, onde os componentes linfoides e epiteliais são substituídos por tecido frouxo e adiposo (McGavin \& Zachay, 2013), tornando sua visualização praticamente impossível (Colville, 2011). Por ser composto de elementos linfoides e epiteliais, é possível que um desses elementos, ou os dois, sirvam como células de origem para neoplasias. Dentre elas são descritos os linfo sarcomas tímicos, que acometem principalmente felinos e bovinos jovens, e os timomas linfo epiteliais que são bem menos comuns e distinguíveis apenas histologicamente pela presença de células neoplásicas epiteliais, associadas aos linfócitos neoplásicos (McGavin \& Zachay, 2013).

O timoma é uma neoplasia localizada no mediastino cranial composto por epitélio tímico e inclui, normalmente, vários graus de infiltração linfocítica benigna geralmente não invasiva, mas pode estar aderida ao pericárdio (Künzel et al., 2012). Normalmente são nodulares e encapsuladas, causando compressão de órgãos adjacentes (Künzel et al., 2012). De modo frequente, são massas císticas e podem apresentar áreas de necrose. A consistência varia de macia a firme, têm coloração branco-acinzentada e, ao corte, podem apresentar áreas de coloração vermelho-enegrecida, caracterizando pontos hemorrágicos e necróticos (Stannard \& Pulley, 1978).

O timoma é considerado benigno quando encapsulado e não invade macroscopicamente tecidos adjacentes, e considerado maligno quando acomete veia cava cranial, traqueia, esôfago e pericárdio, o que dificulta o procedimento cirúrgico ou torna-o inoperável (Duncan et al., 2010). As metástases são raras (Duncan et al., 2010; Nelson \& Couto, 2015), mas podem acometer pulmões, fígado e ossos (Nelson \& Couto, 2015). Em sua grande maioria, os timomas comportam-se de maneira benigna (Ibrahim et al., 1982). Um fator prognóstico muito importante da sobrevida em pacientes portadores de timoma é a invasão tumoral (Pich et al., 1995). Quando não invasivos e completamente ressecados, apresentam bom prognóstico (Duncan et al., 2010). Em cães com timoma, deve ser considerada a timectomia (Lorenz \& Kornegay, 2006).

A utilização dos exames de imagem e laboratoriais é de grande importância para a detecção de neoplasias torácicas. Métodos para diagnóstico por imagem de massas mediastínicas em animais domésticos incluem: radiografias, ultrassonografia e tomografia computadorizada (Künzel et al., 2012). O diagnóstico definitivo requer avaliação citológica ou exame histopatológico (Moore \& Ogilvie, 2001).

A classificação morfológica da neoplasia é realizada via exame histopatológico e a imuno histoquímica pode ser utilizada para definir sua origem linfo epitelial, realçando células epiteliais neoplásicas e linfócitos não-neoplásicos (Gonzalez et al., 1997). Esse tipo de tumor é diagnosticado normalmente em animais na fase adulta para idosa, sendo de dez anos a idade média dos animais acometidos. Não há evidências com relação a predisposição de sexo ou raça (Meuten, 2016).

As manifestações clínicas descritas em cães são: emagrecimento progressivo, anorexia, apatia, secreção nasal bilateral, dispneia, taquipneia, tosse, cansaço, megaesôfago, regurgitação, êmese (Bandarra et al., 2000). Há relatos de síndrome da veia cava cranial e Miastenia gravis em alguns casos (Lainesse et al., 1996; Peaston et al., 1990).

O objetivo desse trabalho é relatar um caso de timoma epitelial diagnosticado em uma cadela da raça Labrador Retriever, através exames de imagem e citologia, que foi submetida à timectomia via toracotomia lateral e apresentou evolução favorável do quadro.

\section{Relato de caso}

Em janeiro de dois mil e vinte, após receberem a notícia do diagnóstico de um tumor em região de tórax, os tutores de uma cadela da raça Labrador Retriever, com onze anos de idade, providos de todos os exames para uma avaliação, decidiram levá-la para consulta de especialidade oncológica. A queixa principal era de engasgos constantes e de forte intensidade, que aumentara gradativamente no último semestre, somando-se ao aparente cansaço, mesmo em repouso.

O primeiro exame realizado foi a radiografia do tórax em duas projeções sendo constatado em topografia de lobo pulmonar esquerdo e mediastino a presença de uma formação de aproximadamente $9,80 \times 18,74 \mathrm{~cm}$, que deslocava o trajeto traqueal dorsalmente (Figura 1). Na sequência, realizou-se a 
citologia dessa estrutura através do método de punção aspirativa por agulha fina (PAAF) que obtivera diagnóstico sugestivo de lipoma. Para melhor visualizar e definir a localização da massa foi sugerida a tomografia computadorizada.

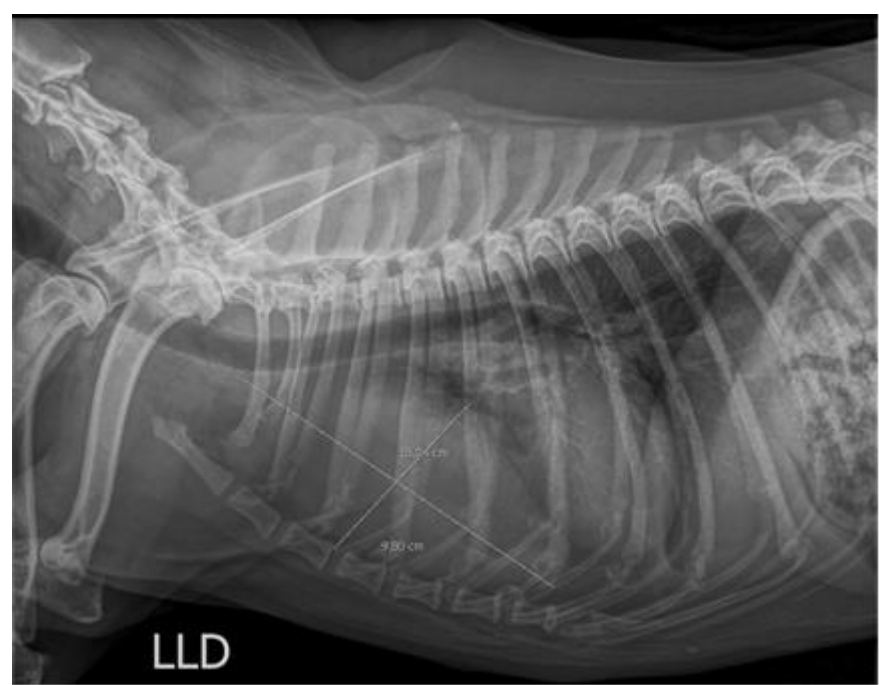

Figura 1. Radiografia torácica projeção LL direita: presença de formação mediastínica que se estende da $1^{\mathrm{a}}$ à $7^{\mathrm{a}}$ esternébra, medindo aproximadamente $9,80 \times 18,74 \mathrm{~cm}$, deslocando órgãos adjacentes dorsalmente. Fonte: Imagem cedida e autorizada pelo tutor, 2020.

O relatório tomográfico descreve uma formação oval de grandes dimensões, limites definidos e contornos regulares, medindo aproximadamente $7,8 \times 8,9 \times 13,5 \mathrm{~cm}$ (eixos ventrodorsal x laterolateral $\mathrm{x}$ craniocaudal), com atenuação de partes moles com realce heterogêneo ao meio de contraste por áreas amorfas fluidas de permeio, em região de mediastino cranial e tendendo para o hemitórax esquerdo, dorsalmente à altura da primeira até a sétima esternébra.

Constatou-se, também, que a formação deslocara estruturas do mediastino cranial (vasos, esôfago, traqueia) e coração dorsolateralmente para a direita, sem plano de separação evidente das artérias e vasos dessa região (subclávia, braquicefálica e veia cava cranial), e da porção ventral da traqueia promovendo deslocamento lateral à direita e redução do seu diâmetro luminal (Figura 2). Além do que, íntimo contato com a parede lateral do ventrículo esquerdo, porção cranial do tronco pulmonar e arco aórtico.
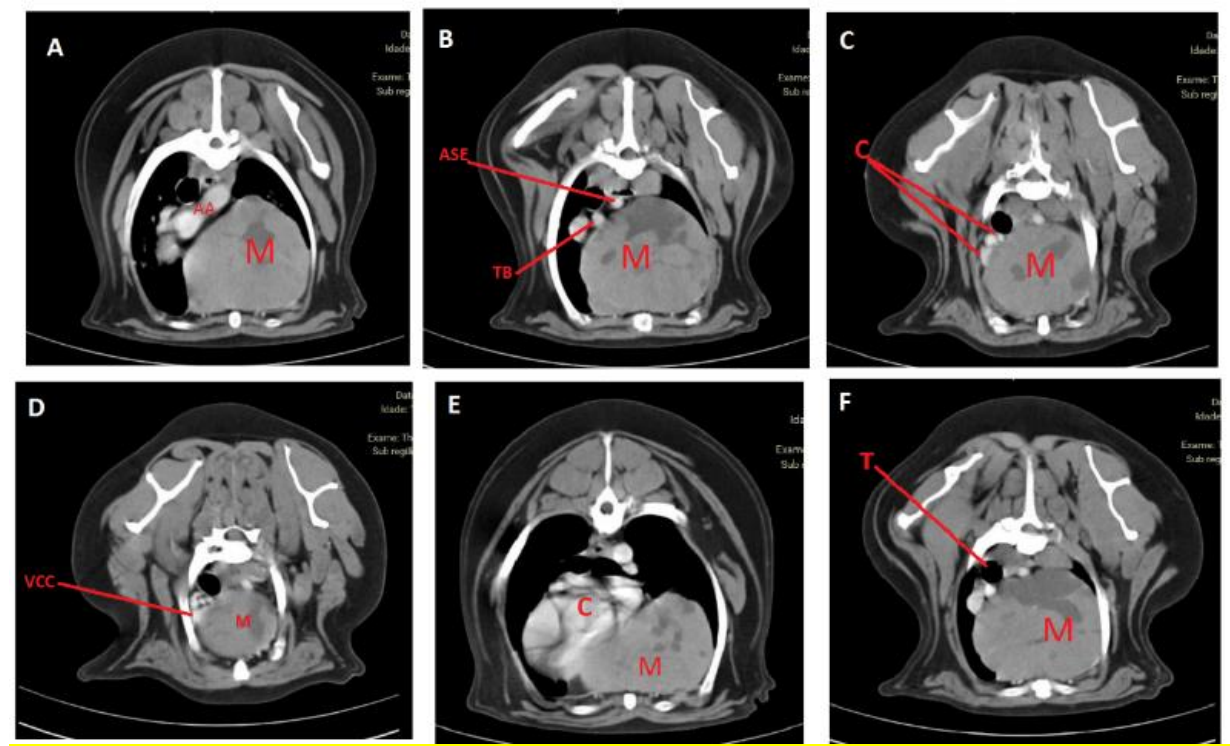

Figura 2. Cortes tomográficos: A) Massa tumoral (M) em contato com o arco aórtico (AA); B) Massa (M) em contato com o tronco braquicefálico (TB) e artéria subclávia esquerda (ASE); C) Carótidas (C) em contato com a massa (M); D) Veia cava cranial (VCC) sendo comprimida pelo tumor (M); E) contato íntimo entre o coração (C) e a neoplasia (M); F) Deslocamento da traqueia (T) para a direita. Fonte: Imagem cedida e autorizada pelo tutor, 2020 
Após esse resultado, realizou-se nova citologia que indicou punção de tecido linfoide provavelmente de porção cortical do timo, com predominância de linfócitos maduros, alguns linfócitos de tamanho intermediário, poucos mastócitos e neutrófilos e ausência de células com características evidentes de malignidade, considerando timoma como principal possibilidade diagnóstica, sendo a cirurgia para remoção o tratamento mais indicado.

Aos exames físico e pré-operatório, as únicas alterações notadas foram o abafamento da ausculta cardíaca e leucocitose por linfocitose no leucograma. No geral, o animal apresentava bom estado de saúde estando apto à realização do procedimento cirúrgico. Em quatorze de janeiro de dois mil e vinte, a paciente foi submetida ao procedimento cirúrgico, sendo realizada a extirpação total do tumor (timectomia) via toracotomia intercostal com ressecção parcial da $4^{\mathrm{a}}$ costela, com acesso pela lateral esquerda. Não havia aderência do tumor aos órgãos adjacentes, facilitando sua total ressecção (Figuras 3A e 3B). Foi fixado um dreno torácico para o restabelecimento da pressão negativa do tórax e drenagem de fluido inflamatório, caso necessário (Figura 4).
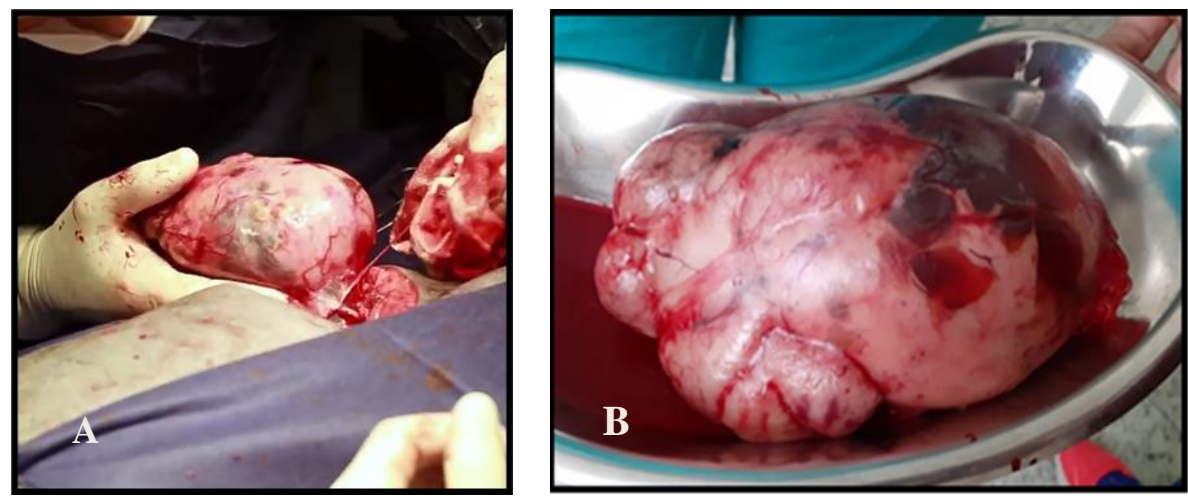

Figura 3. (A). Momento em que o tumor é exposto para o meio extratorácico para total ressecção. (B). Tumor encapsulado, com presença de cistos hemorrágicos e pesando 600 gramas.

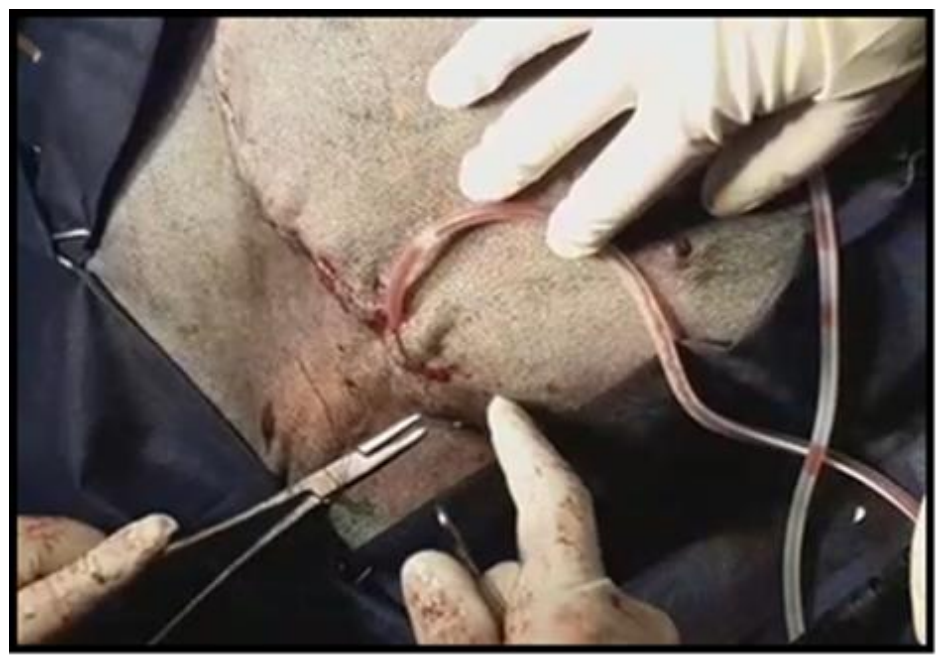

Figura 4. Dreno torácico fixado para drenagem de fluido inflamatório e restabelecimento de pressão negativa intratorácica.

Ao corte, a massa tumoral apresentava coloração acinzentada, áreas de necrose, áreas com cistos hemorrágicos e preservação da cápsula (Figuras 5A e 5B). Foram coletados fragmentos do tumor, fixados em formol à 10\% e encaminhados para análise histopatológica.

A paciente permaneceu 24 horas em tratamento intensivo pós-cirúrgico para um melhor recrutamento dos alvéolos, com ventilação mecânica, que devido a compressão tumoral estavam colapsados. Após 48 horas de evolução favorável, o dreno foi retirado e a paciente recebeu alta. Macroscopicamente, o fragmento enviado para histopatológico apresentou-se irregular, pardacento e de superfície lisa. Ao corte, loculado, macio e pardacento. Histologicamente visualizou-se proliferação de células epiteliais 
neoplásicas com núcleos grandes de cromatina delicada e formato esférico com nucléolos evidentes por vezes proeminentes, associadas a infiltrado de grande quantidade de linfócitos pequenos e reativos. Células epiteliais por vezes formando grupos onde foi possível observar citoplasma abundante de coloração eosinofílica. Foram visualizadas áreas de formações císticas preenchidas por material eosinofílico amorfo finamente granular. Tendo como conclusão diagnóstica: Timoma de origem epitelial.
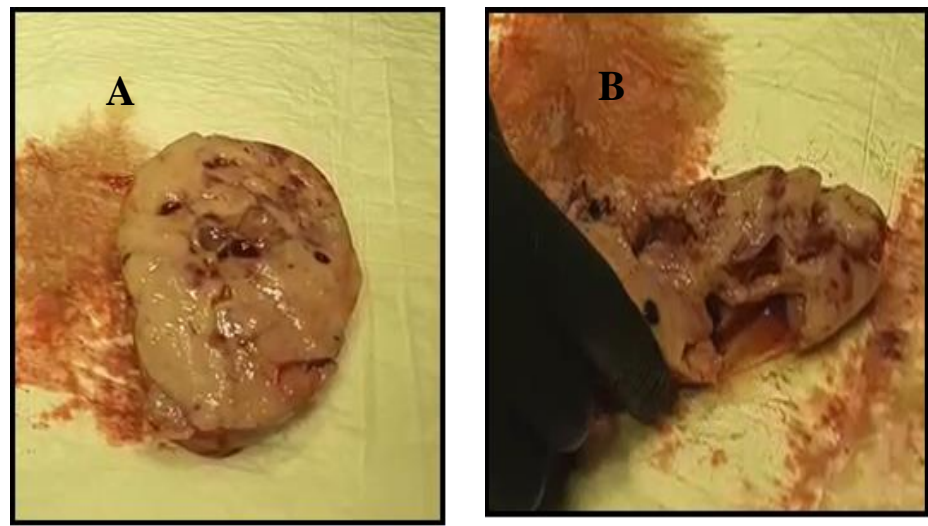

Figura 5. (A) Corte longitudinal da massa tumoral: coloração acinzentada, pontos de necrose e áreas císticas e hemorrágicas; (B) Áreas de necrose liquefativa com conservação da cápsula do órgão.

O exame de imuno-histoquímica não foi realizado nesse caso, pois o tumor era bem definido e foi bem caracterizado por histopatológico. Dezessete dias após a cirurgia, a paciente retornou para a retirada dos pontos e acompanhamento radiográfico (igura 6).

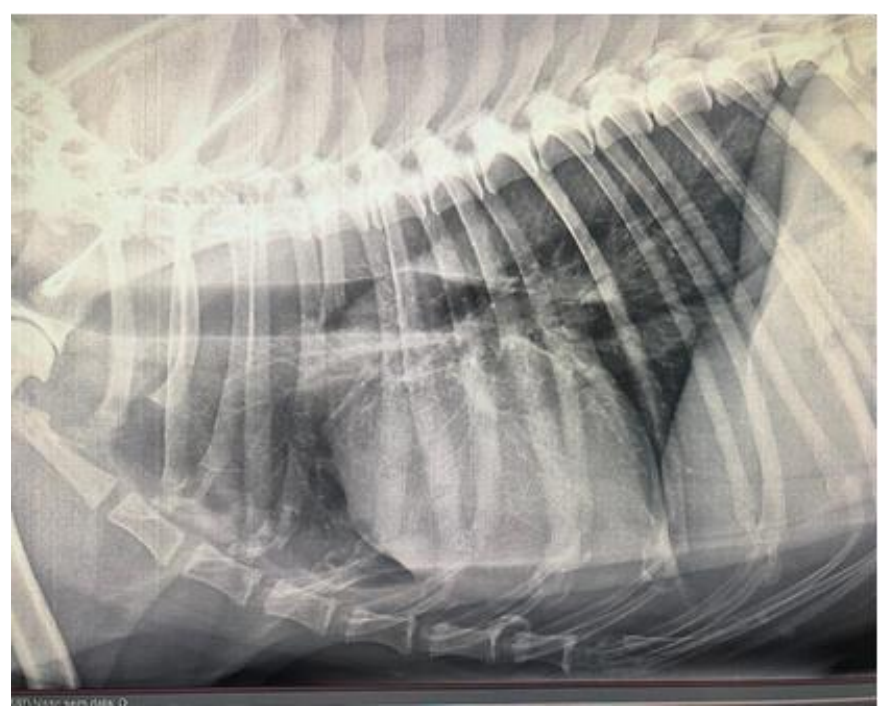

Figura 6. Imagem radiográfica projeção LL: após ressecção total do timoma que ocupava boa parte do toráx, o campo torácico apresenta-se em condições normais de distribuição dos órgãos. Fonte: Imagem cedida e autorizada pelo tutor, 2020.

\section{Discussão}

O timoma é um tumor incomum, já relatado em cães, bovinos, gatos, cavalos, porcos, ovelhas (Valli et al., 2017) e coelho (Repsold, 2019). Segundo Valli et al. (2017), é raramente diagnosticado em cães; porém, quando relatado, eles tendem a ocorrer em animais mais velhos, sem predileção de raça ou sexo. Apesar de a paciente aqui descrita ser idosa, a informação com relação a idade não se faz totalmente verdade, visto que alguns dos artigos consultados para a elaboração desse trabalho descrevem casos diagnosticados em pacientes jovens. 
Dentre os casos de timoma descritos em cães, os relatados por Bandarra et al. (2000), ambos os animais eram jovens e vieram à óbito antes de se instituir qualquer tipo de tratamento devido à complexidade do quadro em que os animais chegaram para o atendimento. Nos exames de imagem dos dois casos foram evidenciados a presença de efusão pleural e edema pulmonar, situação essa, que não foi observado no caso descrito nesse trabalho.

As manifestações clínicas observadas em cães, gatos e coelho, citadas em relatos anteriores, são inespecíficas e descrevem: letargia, perda de peso, secreção nasal bilateral, vômito, regurgitação, exoftalmia (em coelhos), dispneia e intolerância à exercícios (Bandarra et al., 2000; Repsold, 2019). A paciente do presente relato apresentava, segundo os tutores, engasgos frequentes e cansaço fácil, nem ao exame clínico e físico fora notada qualquer outra manifestação. Segundo Bandarra et al. (2000), a localização e o crescimento lento dos timomas, levam ao aparecimento tardio das manifestações clínicas, o que, muitas vezes, não permite o diagnóstico precoce e um bom prognóstico para o paciente. No caso relatado, o diagnóstico foi feito em um Labrador Retriever com onze anos de idade, o que corrobora a descrição de evolução lenta desse tipo de tumor como cita o autor, visto que, o timo se forma na fase fetal e fisiologicamente regride após a puberdade. O prognóstico dessa paciente era reservado, pois não se tinha conhecimento da proporção que o tumor havia tomado e se havia aderência aos órgãos vitais adjacentes. Todavia, a clínica do animal era boa e as manifestações clínicas ainda eram brandas, comparadas aos trabalhos que relatam casos da mesma natureza.

Os timomas tendem a ter evolução lenta, mas podem, raramente, invadir tecidos e metastatizar a pleura e outras áreas das regiões torácica e abdominal, embora a probabilidade de que isso ocorra pareça baixa (Morrisey \& McEntee, 2005). No caso relatado, não foram identificadas metástases nos exames pré-operatório, além do que, o tumor era encapsulado e o histopatológico realizado concluiu que era uma neoplasia benigna. Segundo Bergh et al. (1978), embora esses timomas encapsulados sejam chamados de benignos, isso se torna relativo quando se analisa o quão invasivos eles são. Dessa maneira, os timomas podem ser classificados em malignos e benignos, histologicamente de difícil separação, sendo o achado cirúrgico o que realmente define a malignidade: a) se há o acometimento de estruturas adjacentes (pulmão, pleura, pericárdio, grandes vasos, diafragma); b) e a presença de metástases intra ou extratorácicas (Pêgo-Fernandes et al., 2001). Já os autores Willcox et al. (1995), quando abordam o tema, esclarecem que a rotulá-lo como maligno ou benigno é incorreto, pois todos são potencialmente invasivos e devem ser considerados malignos. Tal ponto de vista pôde ser confirmados através de diversos relatos, como por exemplo o descrito pelos autores Bandarra et al. (2000), em que o tumor era encapsulado e bem delimitado, porém, o tamanho e a localização comprometeram órgãos vitais e levaram o animal à óbito.

A massa tumoral retirada da paciente do presente relato comprometia boa parte da cavidade torácica, além de causar o desvio traqueal e comprimir o esôfago e uma porção do lobo pulmonar esquerdo. Contudo, a paciente não apresentou dispneia e nem mudança de comportamento expressivo. Segundo Bandarra et al. (2000), na maioria dos casos, quando diagnosticada, a neoplasia já atingiu volume suficiente para comprimir estruturas vitais e levar o animal à óbito por insuficiência cardiorrespiratória.

Foram realizadas duas análises citológicas da massa mediastinal existente na paciente discorrida nesse relato. O primeiro laudo sugeriu lipoma e o segundo timoma. O exame citológico é recomendado e pode facilitar no diagnóstico. No entanto, segundo Patsikas et al. (2016), o exame citológico é muitas vezes ilusório e a única maneira de determinar um diagnóstico definitivo de timoma é por avaliação histológica. É comum resultados negativos serem relatados (Lara-Garcia et al., 2008). Isso se faz verdade no caso aqui descrito, visto que houve divergência entre os laudos citológicos e o diagnóstico foi confirmado com o histopatológico. O exame citológico do timoma demonstra o predomínio de linfócitos maduros, células epiteliais e mastócitos (Ibrahim et al., 1982; Moore \& Ogilvie, 2001). Exatamente como visto no caso da paciente descrita em que, um dos exames citológicos realizado, descreve a predominância de linfócitos maduros, alguns linfócitos de tamanho intermediário, poucos mastócitos e neutrófilos e células sem características evidentes de malignidade.

Além da classificação pelo grau de invasão, o timoma é classificado histologicamente de acordo com a predominância celular linfocítica ou epitelial (Nielsen, 1983). No caso da paciente do presente relato, o laudo citológico descreve que há suspeita de que as células puncionadas do tumor são da porção 
cortical do timo, o que sugerem ser de origem epitelial. Lewis et al. (1987) acreditam que, como ocorre grande variação na composição celular tumoral, não há relação consistente entre a microscopia e o comportamento biológico dessas neoplasias, considerando que essa classificação está fracamente ligada ao prognóstico. Todavia, os autores Blumberg et al. (1995) descrevem que em humanos, o tipo linfocítico tem prognóstico mais favorável em comparação ao epitelial, tendo sido encontradas, em $90 \%$ dos casos, taxas de sobrevida de dez anos.

A tomografia computadorizada (TC), em comparação aos outros exames de imagem como a radiografia simples, proporciona ainda informação sobre a capacidade de invasão do timoma (Yoon et al., 2004; Zitz et al., 2008). Também é possível determinar se há compressão da veia cava, deslocamento de vasos, da traqueia ou do coração, além de detectar nódulos pulmonares metastáticos e linfadenopatia (Yoon et al., 2004). Essas informações corroboram para o laudo tomográfico da paciente discorrida nesse relato, que descreve o deslocamento dos mesmos órgãos citados em literatura, além da extensão do tumor, a posição que tende para o lado esquerdo do hemitórax e o íntimo contato com regiões delicadas como a parede lateral do ventrículo esquerdo, porção cranial do tronco pulmonar e arco aórtico, contudo, não é possível definir pela TC se há aderência entre essas estruturas.

Os achados tomográficos do timoma apresentadas nesse estudo são semelhantes às descritas em literatura. Timomas geralmente se apresentam como uma massa mediastinal craniana bem definida, com um contorno liso ou lobulado. Possui atenuação heterogênea causada por lesões internas de cisto de baixa densidade (Tepper et al., 2011). Todavia, há relatos de um padrão de TC semelhante em quimiodectomas e linfomas mediastinais e, portanto, aparentemente não é possível diferenciar timomas de outras neoplasias do mediastino com base apenas na aparência da TC (Yoon et al., 2004). Os exames de imagem, especialmente a tomografia computadorizada, são importantes para amparar as atitudes e possibilidades que o cirurgião terá no decorrer do procedimento: Qual região e lado do tórax será feita a incisão; Qual espaço intercostal ele usará para adentrar a cavidade; Qual costela será resseccionada para facilitar a manipulação; E se continuará a cirurgia caso haja aderência do tumor à outros órgãos. A partir disso, também são repassadas as informações para os tutores preparando-os para qualquer intercorrência que venha a ocorrer.

A excisão cirúrgica do timoma ou timectomia é o tratamento de escolha para a maioria dos timomas, a toracotomia exploratória também é recomendada para avaliar a capacidade de invasão desse tipo de tumor (Culp, 2013). Geralmente, timomas são removidos através de esternotomia mediana, embora haja casos em que a excisão é realizada através de toracotomia lateral (Culp, 2013). No caso da paciente descrita, o acesso foi pela lateral esquerda, pois a TC indicou que a massa tendia para esse lado, e pelo espaço intercostal com ressecção da $4^{\mathrm{a}}$ costela por possibilitar melhor visualização das estruturas presentes na cavidade torácica e do próprio tumor, facilitando a manipulação, preservando os órgãos vitais e realizando a timectomia total sem complicações.

Segundo a literatura, na análise histopatológica de timomas são observadas células epiteliais poligonais, eixo ou cuboide com rodada para núcleos ovais ou reniforme. Nucléolos raramente são vistos, embora em alguns casos eles possam ser grandes e proeminentes. O citoplasma é geralmente levemente eosinofílico. A maioria dos linfócitos é pequeno, mas, linfócitos médios e grandes também podem ser observados (Rae et al., 1989). Essas descrições conferem em boa parte com o que foi observado na paciente deste relato, com a ressalva do citoplasma que apresentou abundante coloração eosinofílica e dos nucléolos que eram evidentes. Pêgo-Fernandes et al. (2001) retrata que é difícil definir fatores prognósticos para timoma, já que estes tumores são incomuns, polimórficos e de crescimento lento. Dessa forma, seria necessário estudar muitos pacientes, por um longo período, para análise dos fatores prognósticos. Os autores Pich et al. (1995) citam que a invasão tumoral é tida como um fator prognóstico muito importante da sobrevida em pacientes portadores de timoma.

Para fins de tratamento, o mais importante é saber se o tumor é ou não operável. A ressecabilidade é baseada na disseminação do tumor pelos tecidos adjacentes ou outros órgãos, bem como sobre a saúde do paciente ser ou não suficiente para suportar uma cirurgia (Equipe Oncoguia, 2017). A ressecção do tumor foi a melhor escolha, levando em consideração a não disseminação do tumor e o ótimo estado de saúde em que a paciente se encontrava. Em resumo, esses tumores, quando não invasivos e ressecados completamente, apresentam bom prognóstico imediato e tardio (Pêgo-Fernandes et al., 2001). 


\section{Conclusão}

Em suma, aproximadamente quinze dias após o diagnóstico inicial de timoma a paciente foi submetida a timectomia com resultado absolutamente favorável. O diagnóstico foi confirmado por meio do exame histopatológico e a paciente recebeu alta. Até então, em torno de 330 dias após o procedimento cirúrgico, a paciente encontra-se em ótimo estado de saúde.

\section{Referências}

Bandarra, E. P., Sequeira, J. L., Moura, V. M. B. D. de, \& Ferreira, H. (2000). Timoma em cão. Relato de caso. Brazilian Journal of Veterinary Research and Animal Science, 37(5), 400-404. https://doi.org/10.1590/s1413-95962000000500010.

Bergh, N. P., Gatzinsky, P., Larsson, S., Lundin, P., \& Ridell, B. (1978). Tumors of the thymus and thymic region: I. Clinicopathological studies on thymomas. The Annals of Thoracic Surgery, 25(2), 91-98. https://doi.org/10.1016/S0003-4975(10)63500-X.

Blumberg, D., Port, J. L., Weksler, B., Delgado, R., Rosai, J., Bains, M. S., Ginsberg, R. J., Martini, N., McCormack, P. M., \& Rusch, V. (1995). Thymoma: a multivariate analysis of factors predicting survival. The Annals of Thoracic Surgery, 60(4), 908-914. https://doi.org/10.1016/00034975(95)00669-C.

Colville, T. (2011). Anatomia e fisiologia clínica para medicina veterinária. Elsevier Brasil.

Culp, W. T. N. (2013). Surgical treatment of thymic disease. In E. Monnet (Ed.), Small animal soft tissue surgery (pp. 72-81). John Wiley \& Sons.

Duncan, B., Lascelles, X., \& White, R. N. (2010). Tumours of the respiratory system and thoracic cavity. In D. J.M., D. B., \& L. X. (Eds.), BSAVA Manual of canine and feline oncology (pp. 265-288).

Equipe Ooncoguia. Estadiamento do Câncer de Timo - Disponível em: http://www.oncoguia.org.br/conteudo/estadiamento-do-cancer-de-timo/4702/617; Acessado em: 27 abr. 2020; Data de atualização: 05/06/2017.

Gonzalez, M., Rodriguez, A., Pizarro, M., \& Llorens, P. (1997). Immunohistochemical study of a noninvasive canine thymoma: A case report. Journal of Veterinary Medicine Series A, 44(1-10), 399 406. https://doi.org/10.1111/j.1439-0442.1997.tb01125.x.

Ibrahim, N. B., Briggs, J. C., Jeyasingham, K., \& Owen, J. R. (1982). Metastasising thymoma. Thorax, 37(10), 771-773.

Köning, H. E., \& Liebich, H. G. (2011). Anatomia dos animais domésticos texto e atlas colorido. Editora Artmed.

Künzel, F., Hittmair, K. M., Hassan, J., Dupré, G., Russold, E., Arespachochaga, A. G., FuchsBaumgartinger, A., \& Bilek, A. (2012). Thymomas in rabbits: clinical evaluation, diagnosis, and treatment. Journal of the American Animal Hospital Association, 48(2), 97-104. https://doi.org/10.5326/JAAHA-MS-5683.

Lainesse, M. F., Taylor, S. M., Myers, S. L., Haines, D., \& Fowler, J. D. (1996). Focal myasthenia gravis as a paraneoplastic syndrome of canine thymoma: improvement following thymectomy. Journal of the American Animal Hospital Association, 32(2), 111-117. https://doi.org/10.5326/15473317-32-2111.

Lara-Garcia, A., Wellman, M., Burkhard, M. J., Machado-Parrula, C., Valli, V. E., Stromberg, P. C., \& Couto, C. G. (2008). Cervical thymoma originating in ectopic thymic tissue in a cat. Veterinary Clinical Pathology, 37(4), 397-402. https://doi.org/10.1111/j.1939-165X.2008.00061.x.

Lewis, J. E., Wick, M. R., Scheithauer, B. W., Bernatz, P. E., \& Taylor, W. F. (1987). Thymoma. A clinicopathologic review. Cancer, 60(11), 2727-2743. https://doi.org/10.1002/10970142(19871201)60:11<2727::AID-CNCR2820601125>3.0.CO;2-D.

Lorenz, M. D., \& Kornegay, J. N. (2006). Neurologia veterinária. Manole.

McGavin, D., \& Zachay, J. F. (2013). Bases da patologia em veterinária. Elsevier Brasil.

Meuten, D. J. (2016). Tumors in domestic animals. John Wiley \& Sons.

Moore, A. S., \& Ogilvie, G. K. (2001). Feline oncology: a comprehensive guide to compassionate care. 
Trenton: Veterinary Learning Systems, 191-219.

Morrisey, J. K., \& McEntee, M. (2005). Therapeutic options for thymoma in the rabbit. Seminars in Avian and Exotic Pet Medicine, 14(3), 175-181. https://doi.org/10.1016/j.saep.2005.06.003.

Nelson, R. W., \& Couto, C. G. (2015). Medicina interna de pequenos animais (Issue 1). Elsevier Editora.

Nielsen, S. W. (1983). Classification of tumors in dogs and cats. Journal of the American Animal Hospital Association, 19, 13-52.

Patsikas, M. N., Angelou, V., \& Papazoglou, L. G. (2016). Diagnosis and surgical treatment of thymoma in the cat. Hellenic Journal of Companion Animal Medicine, 5(1), 663-667. https://doi.org/00264733.

Peaston, A. E., Church, D. B., Allen, G. S., \& Haigh, S. (1990). Combined chylothorax, chylopericardium, and cranial vena cava syndrome in a dog with thymoma. Journal of the American Veterinary Medical Association, 197(10), 1354-1356.

Pêgo-Fernandes, P. M., Ebaid, G. X., Galizia, M. S., Marchiori, P., Suso, F. V., \& Jatene, F. B. (2001). Timoma: discussão sobre tratamento e prognóstico. Journal of Pneumulogy, 27(6), 1-14. https://doi.org/10.1590/s0102-35862001000600001.

Pich, A., Chiarle, R., Chiusa, L., Ponti, R., Geuna, M., Casadio, C., Maggi, G., \& Palestro, G. (1995). Long-term survival of thymoma patients by histologic pattern and proliferative activity. The American Journal of Surgical Pathology, 19(8), 918-926. https://doi.org/10.1097/00000478199508000-00007.

Rae, C. A., Jacobs, R. M., \& Couto, C. G. (1989). A comparison between the cytological and histological characteristics in thirteen canine and feline thymomas. The Canadian Veterinary Journal, 30(6), 497-500.

Repsold, B. N. (2019). O uso de diferentes modalidades do diagnóstico por imagem para detecção de timoma em coelho (Oryctolagus cuniculus). VIII Congresso Estadual de Anclivepa, 23.

Sisson, S., Grossman, J. D., \& Getty, R. (1986). Anatomia dos animais domésticos. Interamericana.

Stannard, A. A., \& Pulley, L. T. (1978). Tumors of the skin and soft tissues. In J. E. Moulton (Ed.), Tumors in Domestic Animals (pp. 211-212). University of California Press.

Tepper, L. C., Spiegel, I. B., \& Davis, G. J. (2011). Diagnosis of erythema multiforme associated with thymoma in a dog and treated with thymectomy. Journal of the American Animal Hospital Association, 47(2), e19-e25. https://doi.org/10.5326/JAAHA-MS-5561.

Valli, V. E., Bienzle, D., Meuten, D. J., \& Linder, K. E. (2017). Tumors of the hemolymphatic system. Tumors in Domestic Animals, 5, 203-321. https://doi.org/10.1002/9781119181200.ch7.

Willcox, N., Daugaard, G., \& Rorth, M. (1995). Thymic tumors with myasthenia gravis or bone-marrow dyscrasias and other thymic tumours. In M. Pckham, H. Pinedo, \& U. Veronesi (Eds.), Oxford textbook of oncology. Oxford University Press.

Yoon, J., Feeney, D. A., Cronk, D. E., Anderson, K. L., \& Ziegler, L. E. (2004). Computed tomographic evaluation of canine and feline mediastinal masses in 14 patients. Veterinary Radiology \& Ultrasound, 45(6), 542-546. https://doi.org/10.1111/j.1740-8261.2004.04093.x.

Zachary, J. F., McGavin, D., \& McGavin, M. D. (2012). Bases da patologia em veterinária. Elsevier Brasil.

Zitz, J. C., Birchard, S. J., Couto, G. C., Samii, V. F., Weisbrode, S. E., \& Young, G. S. (2008). Results of excision of thymoma in cats and dogs: 20 cases (1984-2005). Journal of the American Veterinary Medical Association, 232(8), 1186-1192. https://doi.org/10.2460/javma.232.8.1186.

Histórico do artigo:

Recebido: 17 de novembro de 2020 Aceito: 14 de dezembro de 2020

Disponível online: 3 de abril de 2021 .
Licenciamento: Este artigo é publicado na modalidade Acesso Aberto sob a licença Creative Commons Atribuição 4.0 (CC-BY 4.0), a qual permite uso irrestrito, distribuição, reprodução em qualquer meio, desde que o autor e a fonte sejam devidamente creditados 